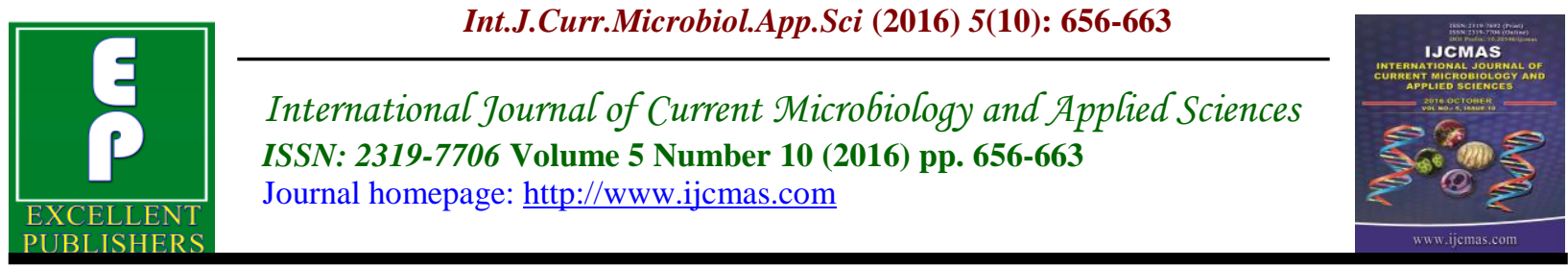

Original Research Article http://dx.doi.org/10.20546/ijcmas.2016.510.073

\title{
Antibiotic Sensitivity Profile of Escherichia coli Associated with Specific Infections in a Nigerian Tertiary Health Institution
}

\author{
M.S. Odimayo ${ }^{1}$, S.I. Nwadioha ${ }^{2}$, Joseph Adejoke Adijat $^{1}$ and \\ Daramola Gabriel Olugbenga ${ }^{3}$
}

${ }^{1}$ Department of Medical Microbiology and Parasitology, College of Medicine, Ekiti State University, Ado Ekiti, Nigeria

${ }^{2}$ Department of Medical Microbiology and Parasitology, College of Health Sciences, Benue

State University, Nigeria

${ }^{3}$ Department of Medical Microbiology and Parasitology, Ekiti State University Teaching

Hospital, Ado Ekiti, Nigeria

*Corresponding author

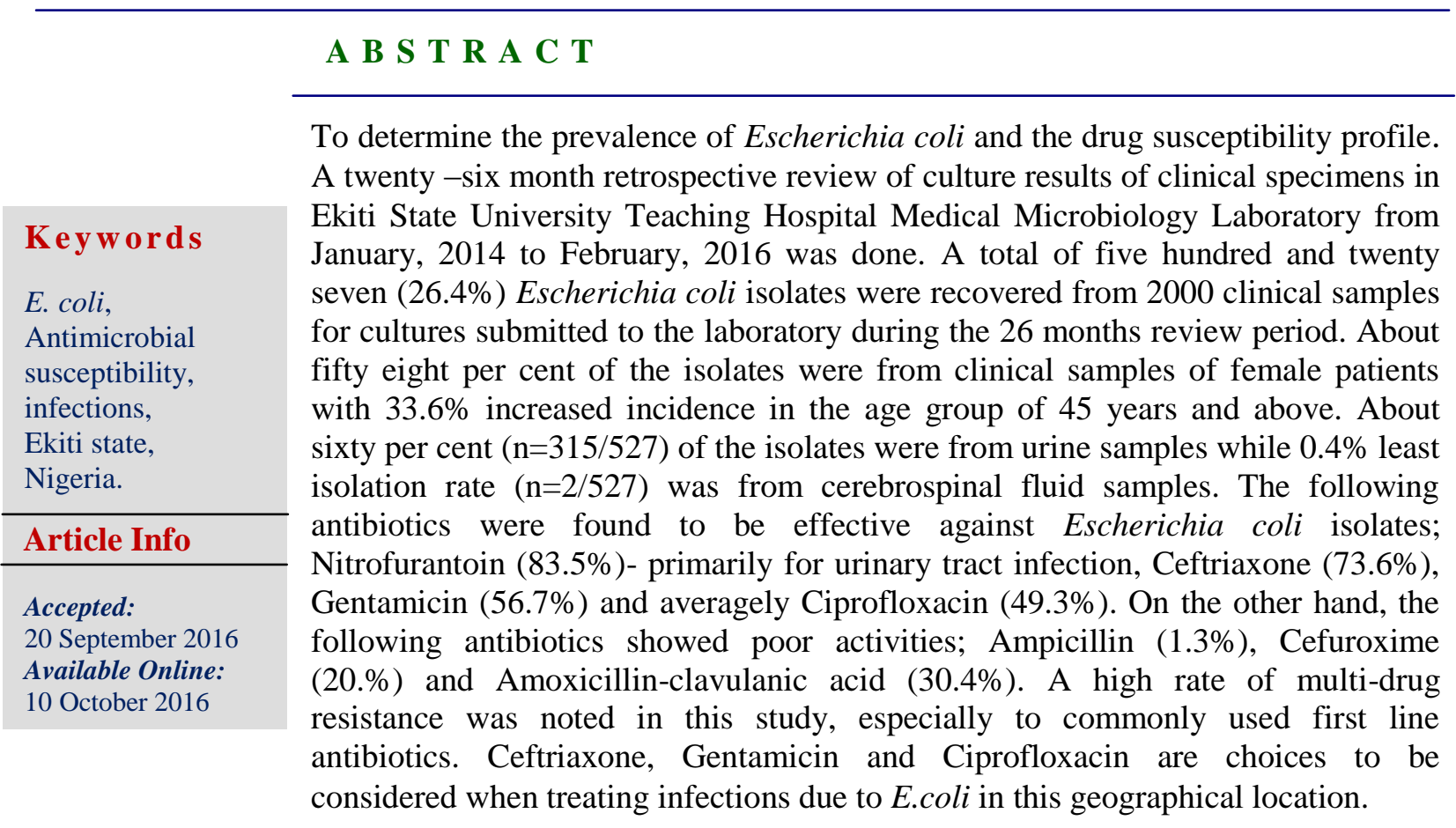

\section{Introduction}

Escherichia coli, abbreviated and often referred to as $E$. coli is a gram-negative, facultative anaerobic, rod-shaped bacterium of the genus Escherichia that is widely distributed in nature and commonly found in the lower intestine of warm-blooded animals and humans. E. coli is the bacterial species most commonly recovered in the clinical laboratories especially from urine samples (Nsofor et al., 2003). It has been incriminated in infectious diseases involving virtually every human tissue and organ system (Washington et al., 2006). E. coli is one of the main causes of both nosocomial 
and community acquired infections in humans, a leading cause of urinary tract, ear, wound and other infections in humans including gram negative sepsis, endotoxininduced shock, meningitis, etc (Monica Cheesbrough, 2010). E. coli is the most frequent cause of community-acquired UTIs and is frequently found to be responsible for intra-abdominal and soft tissue infections.

This hard organism can easily be isolated in the laboratory on some differential/ indicator media such as MacConkey, Cysteine Lactose Electrolyte Deficiency (CLED) media where it grows as Lactose fermenting colony. They are highly motile on wet mount. On Gram staining, they are gram negative rods. They are characteristically identified as positive to Indole reaction test.

The discovery of antimicrobial agents had a major impact on the rate of survival from infections caused by this organism though a rise in bacterial resistance to antibiotics complicates treatment of these infections. The changing patterns of antimicrobial resistance however necessitated the need for new antibacterial agents. Antimicrobial resistance in $E$. coli has been reported worldwide and increasing rates of resistance among $E$. coli is a growing concern in both developed and developing countries (Bell et al., 2002).

Pathogenic isolates of $E$. coli have been reported to have a relatively large potential for developing resistance. Secretion of Extended Spectrum Beta-Lactamases (ESBL) is the main mechanism of developing resistance to antibiotics by the organism. $\beta$-Lactamases continue to be the leading cause of resistance to $\beta$-lactam antibiotics among gram-negative bacteria. $E$. coli strains involved in mixed infections as well as strains isolated from burns have an increased resistance to antibiotics. Most infections caused by ESBL-producing
Escherichia coli (ESBLEC) or Klebsiella pneumoniae had mostly been described as nosocomially acquired or nursing home related. some studies suggest that infections due to ESBL-producing organisms might be an emergent problem in outpatients in different countries (Daza et al., 2011; Garner et al., 1998). In a nationwide study of ESBL-producing organisms carried out in Spain, $51 \%$ of ESBL-producing E. coli (ESBLEC) strains were isolated from outpatients. Oteo et al., in a study carried out in some Spanish hospitals reported that antimicrobial resistance, particularly to fluoroquinolones and third-generation cephalosporins was increasing in E. coli. ${ }^{11}$ In Nigeria there are some reports of high level resistance in $E$. coli infections from extraintestinal sources (Akinduti et al., 2011).

There is a geographical variation in the antibiotic susceptibility pattern of isolates to commonly used antibiotics. This, with the frequency of isolation of $E$. coli in clinical microbiology laboratory because of its involvement in a wide spectrum of human infections and the ease of its isolation, and the emergence of resistance in strains irrespective of the clinical sample and whether patient is hospitalised or out-patient is the basis of carrying out this study in this environment.

The study therefore is aimed at determining the antimicrobial susceptibility pattern of $E$. coli isolated from various clinical samples.

\section{Materials and Methods}

A retrospective review of culture results of all clinical samples submitted to the Medical Microbiology laboratory of Ekiti State University Teaching Hospital from January, 2014 to February, 2016 was done. A total of 2000 samples were received in the laboratory for bacteria culture and 
antimicrobial susceptibility testing during the period under review.

\section{Culture}

Specimens were inoculated on the appropriate media for the isolation of Escherichia coli according to standard culture techniques for culturing on solid agar and broth media was done. Gram staining of isolates was done and biochemical tests such as Triple Sugar Iron (TSI) slope inoculation, Indole test and Motility test were carried out on the isolates from purity plates.

\section{Antibiotic susceptibility testing}

Antibiotic susceptibility testing of isolates was done on dried Mueller Hinton agar plates using the modified Kirby Bauer method according to the Clinical and Laboratory Standards Institute (CLSI), 2006 guidelines on Antimicrobial Susceptibility Testing (Clinical Laboratory Standard Institute, 2008). Standard antibiotic impregnated discs were used which include Ciprofloxacin (5 mcg), Gentamicin (10 mcg), Ofloxacin (30mcg), Augmentin (30mcg), Cotrimoxazole (25mcg), Ceftriaxone (30mcg), Ampicillin (10mcg), Cefuroxime(30mcg), Nitrofurantoin (300mcg). Type culture of Escherichia coli ATCC 25922 served as control strains.

\section{Data Analysis}

The chi square test and percentage proportion were used in analysing collated data. P-value of $<0.05$ was considered to indicate statistically significant differences where applicable.

\section{Results and Discussion}

Table 1 shows that a total of 527 E. coli isolates were recovered from 2000 clinical samples submitted to the laboratory during the 26 months review period. Three hundred and six $(58.1 \%)$ of the isolates was from female patients. As depicted in table 2, the majority of this isolates were from urine samples (59.8\%) and least from cerebrospinal fluid samples $(0.4 \%)$. Figure 1 shows that the age group most affected is the $>45$ years $(33.6 \%)$ while the less than 15 years were the least affected $(10.6 \%)$.

Table 3 shows the antibiotic sensitivity pattern of E. coli from clinical samples. Eight antibiotics were tested against each isolate and Nitrofurantoin was included for urine isolates only. All E. coli from CSF were sensitive to Gentamycin and Ciprofloxacin and resistant to all other antibiotics used. Likewise, E. coli isolated from blood and sputum were all sensitive to ceftriaxone. None of those recovered from CSF, blood and sputum were sensitive to Augmentin, Ampicillin and Cefuroxime. Urine isolates were noted to be generally most sensitive to Nitrofurantoin (83.5\%) while isolates from swab specimen were most sensitive to Ceftriaxone (72.1\%).

Infectious diseases are a common cause of hospital visit and death in the tropics. A larger group of diseases is caused by bacteria and in the past, bacterial diseases were a major cause of death before the advent of antibiotics. The rising incidence of resistance to commonly prescribed antibiotics by bacterial agents has become a global concern.

Of all the clinical specimens submitted to Ekiti State University Teaching Hospital Microbiology laboratory during the period under review, E. coli was found to be a common bacterial isolate, found in a variety of clinical samples like stool, CSF, blood, sputum, urine, semen and swab samples. This amount to an isolation rate of $26.4 \%(n=527 / 2000)$ The $26.4 \%$ finding however is much lower than $63 \%$ isolation rate recorded in Osogbo, S/W Nigeria , 37\% 
16 at Owerri, S/E Nigeria, but higher than $14 \%$ and $14.2 \%$ in Kano, N/E Nigeria and Ethiopia consecutively. A high E. coli prevalence of $59.8 \%$ was isolated from urine samples at a greater frequency than from other clinical specimens. Similar results of $53 \%, 55 \%, 45.5 \%$ were reported in other studies.

A fifty eight per cent peak incidence of Escherichia coli was recovered from female subjects in the study. This is however not surprising for UTI is more common in females than in males because of differences in anatomic structure and changes during sexual maturation, pregnancy, and childbirth (Olowe et al., 2008; Nsofor et al., 2016). Lack of antimicrobial properties of prostatic fluid as in males, hormonal changes which affect the mucosal adherence of bacteria and trauma of urethra during sexual intercourse are also highlighted factors predisposing the female to UTI (Nwadioha et al., 2010). Various studies has also implicated E. coli as the commonest cause of UTI (Olowe et al., 2008; Nsofor et al., 2016; Kibret et al., 2011). From the study, E. coli was recovered $33.6 \%$ mostly from 45years of age and $10 \%$ least in childhood (0-15years old). This is similar to the findings of Kaniz and co-workers in Bangladesh where it was reportedly commoner in the 31-45 years age group and least in the 0-15 years age group. The finding is in keeping with a similar report in Abeokuta, Nigeria where E. coli recovery in urine samples was $58.4 \%$ highest recovery rate in the age group 16-45 years. It may be attributed to frequent sexual intercourse, use of contraceptive spermicidal agents, diaphragms and menopause for women and bladder stasis for older men with prostatic hypertrophy.

Antibiotics commonly prescribed for various infectious disease conditions by physicians in this hospital and environ include
Gentamycin, Augmentin, Ciprofloxacin, Ceftriaxone, Cefuroxime and Ceftazidime hence the need to study the susceptibility of $E$. coli to this commonly prescribed drugs. In this study, $E$.coli isolates from CSF and blood specimens were found to be resistant to almost all antibiotics tested while isolates from urine samples were found to be sensitive to all antibiotics used. Of all the antibiotics tested against urine pathogen, nitrofurantoin is found to be $83.5 \%$ highly sensitive. A similar finding was reported in Ethiopia where significantly high degree of sensitivity rate to nitrofurantoin $(96.4 \%)$ was recorded. The high degree of sensitivity to Nitrofurantoin by urinary tract bacterial pathogens is probably due to its narrow spectrum of activity, narrow tissue distribution and almost no effect outside of the urinary tract.

Resistance against common penicillin derivative like ampicillin was reported in this study .This maybe due to overuse of this drug which is readily available, affordable and can be procured over the counter without prescription. A below average sensitivity was also reported to ofloxacin $(42.5 \%)$ and ciprofloxacin (49.3\%). Increased resistance of $E$. coli against Quinolones may be due to the overuse of these drugs for the treatment of UTI or generalized use of floroquinolones in animals feed which in turn lead to the transmission of resistance mechanism to strains from animals to human (Kaniz, 2016).

From this study, it can be inferred that ampicillin (1.3\%), cefuroxime $(20.5 \%)$ and augmentin $(30.4 \%)$ are less effective on $E$. coli in this environment. Gentamycin, ceftriaxone and, to a lesser extent, ciprofloxacin are choices to be considered when treating infections due to $E$. coli in the study environment. 
Table.1 Distribution of E. coli Isolated From Different Specimens Between Jan. 2014 to Feb. 2016 at Ekiti State University Teaching Hospital, Ado Ekiti.

\begin{tabular}{llllll}
\hline Sample & $\begin{array}{l}\text { Male } \\
\text { n }(\boldsymbol{\%})\end{array}$ & $\begin{array}{l}\text { Female } \\
\mathbf{n}(\boldsymbol{\%})\end{array}$ & $\begin{array}{l}\text { Total } \\
\mathbf{n}(\boldsymbol{\%})\end{array}$ & $\chi^{\mathbf{2}}$ & $\boldsymbol{p}$ value \\
\hline Urine & $138(62.4)$ & $177(57.8)$ & $315(59.8)$ & 22.215 & $0.001^{*}$ \\
Sputum & $9(4.1)$ & $8(2.6)$ & $17(3.2)$ & & \\
Swab & $53(24.0)$ & $112(36.6)$ & $165(31.3)$ & & \\
Semen & $8(3.6)$ & - & $8(1.5)$ & & \\
Stool & $7(3.2)$ & $6(2.0)$ & $13(2.5)$ & & \\
Blood & $5(2.3)$ & $2(0.7)$ & $7(1.3)$ & & \\
C.S.F. & $1(0.4)$ & $1(0.3)$ & $2(0.4)$ & & \\
Total & $\mathbf{2 2 1 ( 4 1 . 9 )}$ & $\mathbf{3 0 6}(\mathbf{5 8 . 1})$ & $\mathbf{5 2 7}(\mathbf{1 0 0 . 0})$ & & \\
\hline
\end{tabular}

Table.2 Quarterly isolation rate of E. coli from different samples

\begin{tabular}{|l|l|l|l|l|l|l|l|l|}
\hline Period & Urine & $\begin{array}{l}\text { Sputu } \\
\text { m }\end{array}$ & Swab & Semen & Stool & $\begin{array}{l}\text { Bloo } \\
\text { d }\end{array}$ & $\begin{array}{l}\text { CSF } \\
\text { Total(\% }\end{array}$ \\
\hline Jan.-March, 2014 & 38 & 2 & 16 & 0 & 2 & 0 & 1 & $\mathbf{5 9}(\mathbf{1 1 . 2})$ \\
\hline April - June, 2014 & 44 & 4 & 26 & 1 & 1 & 1 & 0 & $\mathbf{7 7}(\mathbf{1 4 . 6})$ \\
\hline July - Sept., 2014 & 24 & 3 & 19 & 1 & 1 & 0 & 0 & $\mathbf{4 8}(\mathbf{9 . 1})$ \\
\hline Oct. -Dec., 2014 & 33 & 0 & 13 & 1 & 1 & 1 & 0 & $\mathbf{4 9}(\mathbf{9 . 3})$ \\
\hline Jan.-March, 2015 & 31 & 1 & 23 & 1 & 2 & 0 & 0 & $\mathbf{5 8}(\mathbf{1 1})$ \\
\hline April - June, 2015 & 38 & 2 & 16 & 0 & 1 & 0 & 0 & $\mathbf{5 7 ( 1 0 . 8 )}$ \\
\hline July - Sept., 2015 & 25 & 1 & 20 & 0 & 4 & 2 & 0 & $\mathbf{5 2 ( 9 . 9 )}$ \\
\hline Oct.-Dec., 2015 & 61 & 4 & 20 & 0 & 1 & 3 & 0 & $\mathbf{8 9}(\mathbf{1 6 . 9})$ \\
\hline Jan.-Feb., 2016 & 21 & 0 & 12 & 4 & 0 & 0 & 1 & $\mathbf{3 8}(\mathbf{7 . 2})$ \\
\hline Total(\%) & $\mathbf{3 1 5}$ & $\mathbf{1 7}$ & $\mathbf{1 6 5}$ & $\mathbf{8}$ & $\mathbf{1 3}$ & $\mathbf{7}$ & $\mathbf{2}$ & $\begin{array}{l}\mathbf{5 2 7} \\
(\mathbf{1 0 0}\end{array}$ \\
\hline
\end{tabular}

Table.3 Antibiotic Sensitivity Pattern of E. coli Isolated from the Clinical Specimens

\begin{tabular}{|l|l|l|l|l|l|l|}
\hline Antibiotics & $\begin{array}{l}\text { Urine } \\
\mathrm{n}=315(\%)\end{array}$ & $\begin{array}{l}\text { Swab } \\
\mathrm{n}=165(\%)\end{array}$ & $\begin{array}{l}\text { CSF } \\
\mathrm{n}=2(\%)\end{array}$ & $\begin{array}{l}\text { Blood } \\
\mathrm{n}=7(\%)\end{array}$ & $\begin{array}{l}\text { Sputum } \\
\mathrm{n}=17(\%)\end{array}$ & $\begin{array}{l}\text { Total } \\
\mathrm{N}=527(\%)\end{array}$ \\
\hline Gentamycin & $185(58.7)$ & $103(62.4)$ & $2(\mathbf{1 0 0})$ & $0(0)$ & $9(52.9)$ & $299(56.7)$ \\
\hline Ofloxacin & $189(60)$ & $17(10.3)$ & $0(0)$ & $5(71.4)$ & $13(76.5)$ & $224(42.5)$ \\
\hline Ciprofloxacin & $156(49.5)$ & $93(56.4)$ & $2(\mathbf{1 0 0})$ & $2(28.6)$ & $7(41.2)$ & $260(49.3)$ \\
\hline Augmentin & $111(35.2)$ & $49(29.7)$ & $0(0)$ & $0(0)$ & $0(0)$ & $160(30.4)$ \\
\hline Cotrimoxazole & $163(51.7)$ & $85(51.5)$ & $0(0)$ & $0(0)$ & $7(41.2)$ & $255(48.4)$ \\
\hline Ceftriaxone & $245(\mathbf{7 7 . 8})$ & $119(\mathbf{7 2 . 1})$ & $0(0)$ & $7(\mathbf{1 0 0})$ & $17(\mathbf{1 0 0})$ & $388(\mathbf{7 3 . 6})$ \\
\hline Ampicillin & $4(1.3)$ & $0(0)$ & $0(0)$ & $0(0)$ & $0(0)$ & $4(1.3)$ \\
\hline Cefuroxime & $35(11.1)$ & $73(44.2)$ & $0(0)$ & $0(0)$ & $0(0)$ & $108(20.5)$ \\
\hline Nitrofurantoin & $263(83.5)$ & *NA & NA & NA & NA & $263(83.5)$ \\
\hline
\end{tabular}

*NA: not applicable 
Fig.1 Age Distribution of Patients whose Clinical Specimens were Infected with E. coli

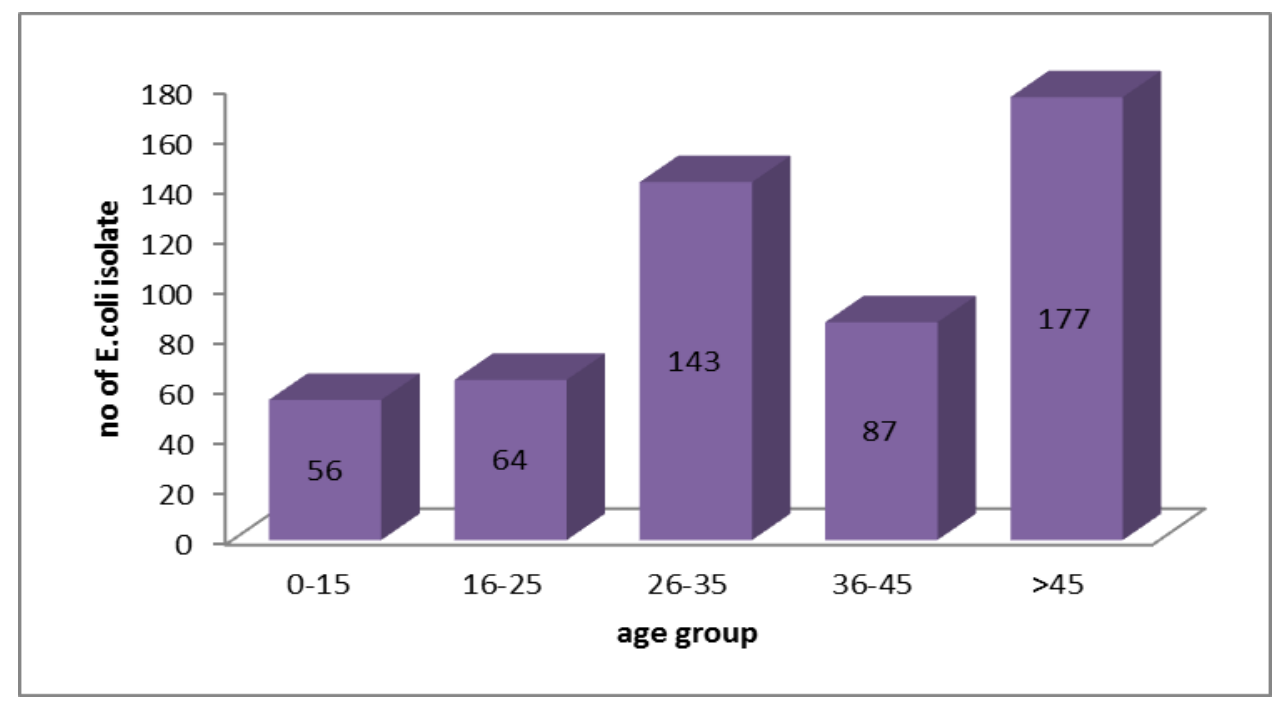

A similar study carried out in Bangladesh, Nepal, India and North America concluded that Co-trimoxazole and Nalidixic acid were virtually useless against $E$. coli. Of note in this study is the high rate of resistance to antibiotics and this further confirms earlier reports that various reservoir sources of multi-resistant clones of $E$. coli carrying mobile genetic elements capable of epidemic spread are present in our locality. This has a public health implication as an outbreak of E. coli, especially the Extended Spectrum Beta -Lactamase enzyme (ESBL), Carbapenemases enzyme multi-drug resistant strains is a possibility (Jacobson $e t$ al., 2008).

In conclusion, a high rate of multi-drug resistance was noted in the study, especially to commonly used first line antibiotics. Gentamycin, ceftriaxone and ciprofloxacin are choices to be considered when treating infections due to $E$. coli in this geographical location.

\section{Recommendation}

Regular antimicrobial susceptibility surveillance is recommended and common antibiotics to which resistance is being noted could be withdrawn from circulation.

\section{References}

Akinduti, P.A., Oluwadun, A., Iwalokun, B.A., Oluwaseun, E. 2011. Clonal dissemination of blaTEM $\beta$-Lactamase strains among enteric isolates in Abeokuta, Nigeria. Res. J. Microbiol., 6(12): 919-925.

Amit, R.S., Dwij, R.B., Jyotsna, S., Megha, R.B. 2013. Antimicrobial Susceptibility Pattern of Escherichia coli Isolated from Urinary Tract Infected Patients Attending Bir Hospital. Nepal J. Sci. Technol., 14(1): $177-184$

Bell, J.M., Turnidge, J.D., Gales, A.C., Pfaller, M., Jones, R.N., Sentry, A.P.A.C. 2002. Study Group, author. Prevalence of extended spectrum betalactamase (ESBL)-producing clinical isolates in the Asia-Pacific region and South Africa: regional results from SENTRY Antimicrobial Surveillance Program (1998-99). Diagnostic Microbiol. Infect. Dis., 42: 193-198.

Clinical Laboratory Standard Institute 
(CLSI) 2008. Performance Standard for Antimicrobial Disk Susceptibility Tests; $18^{\text {th }}$ informational supplements. CLSI document standard M10-S18. Wayne(PA).

Daza, R., Gutierrez, J., Piedrola, G. 2011. Antibiotic susceptibility of bacterial strains isolated from patients with community-acquired urinary tract infections. Int. J. Antimicrobial Agents, 18: 211-215. CrossRefMedline

El Kholy, A., Baseem, H., Hall, G., Procop, G.W., Longworth, D.L. 2003. Antimicrobial resistance in Cairo, Egypt 1999-2000: a survey of five hospitals. J. Antimicrobial Chemother., 51: 625-630. [PubMed]

Garner, J.S., Jarvis, W.R., Emori, T.J., Horan, T.C. 1998. CDC definitions for nosocomial infections. American $J$. Infect. Control, 16: 128-140. CrossRefMedline

Goldstein, F.W. 2000. Antibiotic susceptibility of bacterial strains isolated from patients with community-acquired urinary tract infections in France. European J. Clin. Microbiol., $\quad 19$ : $112-117$. CrossRefMedline

Jacobson, S.M., Stickler, D.J., Mobley, H.L. 2008. Complicated catheter-associated urinary tract infections due to $E$. coli and Proteus mirabilis. Clin. Microbiol. Rev., 21: 26-59.

Jesús, R.B., Navarro, M.D., Romero, L., Martínez, L.M., Miguel, A.M. 2004. Epidemiology and Clinical Features of Infections Caused by ExtendedSpectrum Beta-Lactamase-Producing Escherichia coli in Nonhospitalized Patients. J. Clin. Microbiol., 42(3): 1089-1094.

Kaniz, F., Sohana, S., Suvamoy, D. 2016. Isolation, identification and antimicrobial susceptibility pattern analysis of Escherichia coli isolated from clinical samples of Bangladesh. Asian J. Biomed. Pharma. Sci., North America, Available at: <http://www.jbiopharm.com/index.ph p/ajbps/article/view/795>. Date accessed: 28 Jun. 2016.

Kaper, J.B., Ntaro, J.P., Mobley, H.L.T. 2012. Pathogenic E. coli. Nature Rev. Microbiol., 2: 30-40.

Karlowsky, J.A., Kelly, L.J., Thornsberry, C., Jones, M.E., Sahm, D.F. 2002. Trends in Antimicrobial Resistance among Urinary Tract Infection Isolates of Escherichia coli from Female Outpatients in the United States. Antimicrobial Agents of Chemother., 46(8): 2540-2545.

Kibret, M., Abera, B. 2011. Antimicrobial susceptibility patterns of $E$. coli from clinical sources in northeast Ethiopia. African Health Sci., 11(1): S40-S45.

Monica Cheesbrough. 2010. District Laboratory Practice in Tropical Countries. Part 2. Cambridge University Press. UK $.2^{\text {nd }}$ ed.Update, Pp $67-68$.

Motayo, B.O., Ogiogwa, I.J., Okerentugba, P.O., Innocent-Adiele, H.C. 2012. Antimicrobial Resistance Profile of Extra-intestinal Escherichia coli Infections in a South Western Nigerian City. J. Microbiol. Res., 2(5): 141-144

Nsofor, C.A., Iroegbu, C.U., Call, D.R., Davies, M.A. 2003. Genetic relatedness of drug resistant E. coli isolates of human and animal origin in Nigeria. Int. J. Genetic Mol. Biol., 5(3): $37-41$.

Nsofor, C.A., Obima, O., Ohiaeri, G. 2016. Antibiotic susceptibility of $\mathrm{E}$ coli isolates from human and animal specimens in Owerri, Nigeria. Bull. Environ. Pharmacol. Life sci., 5: 3236.

Nwadioha, S.I., Nwokedi, E.E., Kashibu, E. 2010. Antibiotics susceptibility pattern 
of uropathogenic bacterial isolates from community and hospital acquired urinary tract infections in a Nigerian Tertiary Hospital. Int. J. Microbiol., 2: 105-109.

Olowe, O.A., Okanlawon, B.M., Olowu, R.A., Olayemi, A.B. 2008. Antimicrobial resistant pattern of $E$. coli from human clinical samples in Osogbo, SW Nigeria. Africa $J$. Microbiol. Res., 2: 8-11.

Oteo, J., Campos, J., Baquero, F. 2002.
Antibiotic resistance in 1962 invasive isolates of Escherichia coli in 27 Spanish hospitals participating in the European Antimicrobial Resistance Surveillance System. J. Antimicrobial Chemotherapy, 50: 945-952.

Washington, C.W., Stephen, D.A., William, M.J., Elmer, W.K., Gary, W.P., Gary, W.P.1. 2006. Koneman'sColor Atlas and Textbook of Diagnostic Microbiology. 6th ed. 2006.Pp235

\section{How to cite this article:}

Odimayo, M.S., S.I. Nwadioha, Joseph Adejoke Adijat and Daramola Gabriel Olugbenga. 2016. Antibiotic Sensitivity Profile of Escherichia coli Associated with Specific Infections in a Nigerian Tertiary Health Institution. Int.J.Curr.Microbiol.App.Sci. 5(10): 656-663. doi: http://dx.doi.org/10.20546/ijcmas.2016.510.073 